\title{
On a decision rule supported by a forecasting stage based on the decision maker's coefficient of optimism
}

\author{
Helena Gaspars-Wieloch
}

Published online: 28 October 2014

(C) The Author(s) 2014. This article is published with open access at Springerlink.com

\begin{abstract}
The paper contains a description of a new approach (called the SF + AS method, i.e. the scenario forecasting + alternative selection method) that can be used in decision making under uncertainty when pure optimal strategies are sought-after. This procedure takes into consideration the level of decision maker's coefficient of optimism (or coefficient of pessimism) and consists of two stages: the true scenario forecasting (on the basis of the decision maker's preferences) and the appropriate alternative selection by taking into account the payoffs of the appointed true scenario or the most probable scenarios. In contradiction to existing decision rules, this procedure assumes that the decision making process should involve only a part of the payoff matrix because only one state of nature will occur in the end. The second essential difference between the SF + AS method and other decision rules is that in the first one there is an attempt to appoint globally the best and the worst scenario (regardless the alternative considered). Meanwhile, other procedures determine the status of a given event depending on the decision.
\end{abstract}

Keywords Decision making - Uncertainty · Pure strategy · True scenario forecasting $\cdot$ Coefficient of optimism $\cdot$ Coefficient of pessimism

\section{Introduction}

In most cases we are not able to anticipate the future effectively, which means that we make our decisions (i.e. choose the appropriate alternative) under uncertainty or under risk. Possible scenarios (states of nature) are predicted by experts or by the decision maker (DM). Decision making under uncertainty (DMUU) occurs when the probability

\footnotetext{
H. Gaspars-Wieloch ( $ه)$

Poznan University of Economics, al. Niepodeglosci 10, 61-875 Poznan, Poland

e-mail: helena.gaspars@ue.poznan.pl
} 
Table 1 Payoff matrix (general case)

\begin{tabular}{llll}
\hline Scenarios and decisions & $D_{1}$ & $D_{j}$ & $D_{n}$ \\
\hline$S_{1}$ & $a_{11}$ & $a_{1 j}$ & $a_{1 n}$ \\
$S_{i}$ & $a_{i 1}$ & $a_{i j}$ & $a_{i n}$ \\
$S_{m}$ & $a_{m 1}$ & $a_{m j}$ & $a_{m n}$ \\
\hline
\end{tabular}

of those states of nature is not known or when the decision maker does not want to make use of the estimated probability distribution. If the likelihood of particular scenarios is known and significant for the decision maker, then we deal with decision making under risk (DMUR) (Chronopoulos et al. 2011; Groenewald and Pretorius 2011; Haimann et al. 1985; Knight 1921; Render et al. 2006; Trzaskalik 2008). These two categories (uncertainty and risk) were formally integrated in economic theory by von Neumann and Morgenstern (1944). It is worth mentioning that there is also a third category, decision making with partial (incomplete) information (DMPI), which is characterized by probability distributions not known completely (Cannon and Kmietowicz 1974; Kmietowicz and Pearman 1984; Kofler 1993; Michalska 2014; Weber 1987). In this contribution we will focus on DMUU which seems to be more frequent in realistic decision problems (Xiaogang and Rongwei 2012). The result of the choice made by the decision maker under uncertainty depends on two factors: which decision will be selected (internal factor) and which scenario will occur in the future (external factor). In contradiction to $n$-person games (where players are conscious adversaries), within games against nature the last one plays a passive role and is a neutral opponent (Luce and Raiffa 1957; Officer and Anderson 1968). DMUU may be presented with the aid of a profit or payoff matrix (Table 1) where $m$ is the number of mutually exclusive scenarios (let us denote them by $S_{1}, S_{2}, \ldots, S_{m}$ ), $n$ signifies the number of decisions $\left(D_{1}, D_{2}, \ldots, D_{n}\right)$ and $a_{i j}$ is the profit connected with scenario $S_{i}$ and alternative $D_{j}$. The goal of the DM consists in selecting the decision which maximizes the profit.

Note that in order to avoid too many repetitions, we will use the following notions as synonyms:

$$
\begin{aligned}
& \text { - "scenarios" = "states of nature" = "events", } \\
& \text { - "decisions" = "alternatives". }
\end{aligned}
$$

Sometimes the distribution of payoffs connected with particular alternatives is not discrete and then the profits for each decision $D_{j}$ belong to an interval $\left[w_{j}, m_{j}\right]$ (Branzei et al. 2011; Gaspars-Wieloch 2013a, 2014b; Huynh et al. 2009). In this paper we will focus on the scenario approach for DMUU which has a lower degree of uncertainty than the interval approach because only several outcomes from this range may occur.

In the uncertainty case the decision maker may search an optimal pure strategy or an optimal mixed strategy. A pure strategy is a solution assuming that the decision maker chooses and completely executes one and only one alternative. Meanwhile the mixed strategy (mixed acts, mixed actions) allows the decision maker to select and perform a weighted combination of several accessible alternatives, see e.g. bonds portfolio construction, cultivation of different plants (Gaspars-Wieloch 2014a; Officer 
and Anderson 1968; Puppe and Schlag 2009; Sikora 2008). The whole paper will concern the optimal pure strategy searching.

We will also assume that each alternative is characterized by one criterion value or by one synthetic aggregated value denoting the overall realization of all significant criteria.

The literature offers many procedures applied to DMUU, such as the Wald's criterion (Wald 1950a,b), the maximax criterion described for example in Pazek and Rozman (2009), the maximin joy criterion (Hayashi 2006; Puppe and Schlag 2009); the Hurwicz's criterion (Hurwicz 1951, 1952), the Savage's criterion (Savage 1961; Niehans 1948), the Bayes' (Laplace's) criterion or equality decision criterion (see e.g. Render et al. 2006), which, for convenience, can be called "the classical decision rules"-CD rules (see also Xiaogang and Rongwei 2012), and many diverse extensions or hybrids of these methods (see e.g. Basili 2006; Basili et al. 2008; Basili and Chateauneuf 2011; Basili and Zappia 2010; Chateauneuf and Cohen 2000; Ellsberg 2001; Etner et al. 2012; Gaspars-Wieloch 2013a, 2014b; Ghirardato et al. 2004; Gilboa 2009; Gilboa and Schmeidler 1989; Ioan and Ioan 2011; Karni 1985; Karni et al. 1983; Marinacci 2002; Nakamura 1986; Officer and Anderson 1968; Piasecki 1990; Tversky and Kahneman 1992), which can be named "the extended decisions rules"-ED rules.

In all of them a measure (e.g. the Wald's criterion, the Ellsberg index, the $\alpha$ MEU index, etc.) precisely defined is computed for each alternative, which allows the decision maker to choose in the last step the decision with the most preferable value of the applied index. This measure depends on one, two, several or all payoffs connected with particular decisions.

In the majority of existing methods the alternative is selected on the basis of the level of optimism or the level of risk aversion declared by the decision maker. Please, note that when talking about DM's risk aversion, we do not treat risk as a situation where the probability distribution of each parameter of the decision problem is known, but we mean a danger of incurring losses or a danger of low outcomes occurring, i.e. the possibility that some unfavourable circumstances will happen.

When the decision maker is adventurous, it is recommended to look at the highest payoffs assigned to each decision and to choose the alternative according to the maximax rule (optimism decision criterion). When the DM represents a risk-averse behavior, it is suggested to compare the lowest profits or the highest regrets and to follow the Wald's rule, the maximin joy criterion or the Savage's rule. Finally, when we deal with a moderate DM, the Hurwicz's approach, also called compromised decision criterion, (or diverse extended decision rules) can be used since it enables one to assign a coefficient of pessimism $(\alpha)$ to the worst value and a coefficient of optimism $(\beta=1-\alpha)$ to the best outcome connected with particular strategies in order to obtain a weighted average for each alternative and select a suitable decision. Let us add that both coefficients fulfill the following conditions: $\alpha \in[0,1], \beta \in[0,1]$. They are undoubtedly very subjective, because they are determined by people representing varied attitudes towards future, risk, investments etc. Parameter $\beta$ is close to 1 for extreme optimists, i.e. adventurous decision makers expecting high payoffs (risk-prone behavior), and it tends to 0 for radical pessimists, i.e. cautious decision makers expecting low outcomes (risk-averse behavior). 
Table 2 Payoff matrix-Example I

\begin{tabular}{llll}
\hline Scenarios and decisions & $D_{1}$ & $D_{2}$ & $D_{3}$ \\
\hline$S_{1}$ & 5 & 4 & $3(\min )$ \\
$S_{2}$ & $10(\max )$ & $1(\min )$ & $7(\max )$ \\
$S_{3}$ & $0(\min )$ & $8(\max )$ & 5 \\
\hline
\end{tabular}

It is worth emphasizing that usually the highest and the lowest profit of particular decisions come from different states of nature. That means that a given scenario may be very optimistic from the point of view of one decision and simultaneously-extremely bad with respect to an other alternative (see Table 2, scenarios $S_{2}$ and $S_{3}$ ). Hence, according to the nature of existing methods, scenarios are very seldom considered as totally pessimistic or totally optimistic. Meanwhile, Officer and Anderson (1968) and Milnor (1954) state that each decision rule theoretically destined for games against nature, which treats nature as a conscious opponent who is altering strategies depending on the outcomes, is wrong and unsatisfactory!

Therefore, let us think over the following new question-is it possible to forecast the true state of nature on the basis of the decision maker's coefficient of optimism and to select the appropriate alternative by taking into account not the whole payoff matrix (i.e. the whole set of possible scenarios) but only the scenario (or scenarios) meeting (or nearly meeting) the DM's preferences?

The remainder of the paper is organized as follows. In Sect. 2 the author suggests and describes a new method enabling one to forecast the true state of nature depending on the decision maker's attitude towards risk and to select in the second stage the appropriate alternative. In Sect. 3 the Reader will find a case study. Conclusions are gathered in Sect. 4.

\section{The SF + AS method: description and illustration}

The method presented below (called the SF + AS method, i.e. scenario forecasting and alternative selection method) has been already described in Gaspars-Wieloch (2013b), but in this contribution the description is more formal, extensive and comprehensive.

$\mathrm{SF}+\mathrm{AS}$ appeals to a totally different concept than other procedures do. This time a given scenario will be treated as extremely pessimistic, moderately pessimistic, moderate, moderately optimistic or radically optimistic irrespective of the alternative.

Hence, the heart of the problem consists in applying a suitable tool enabling one to determine correctly the status of each state of nature. This is the first stage of the $\mathrm{SF}+\mathrm{AS}$ method. Possible techniques can be diverse-here, we will use the concept of dominance and the coefficient of optimism declared by the decision maker. After generating a ranking of scenarios by means of the sum of "dominance cases", an interval of values of the coefficient of optimism will be assigned to each state of nature. Obviously, higher the sum of "dominance cases" for a given scenario is, more optimistic this scenario should be. 
The second stage of the SF+AS method concerns the choice of an appropriate decision on the basis of the scenario (scenarios) corresponding to the decision maker's risk aversion.

Let us enumerate the steps of the whole procedure in the general case:

1. Calculate the sum of the "dominance cases" for each scenario (Eqs. 1 and 2).

$$
\begin{aligned}
d_{i j} & =m-\max \left\{p^{j}\left(a_{i j}\right)\right\} \quad i=1, \ldots, m ; j=1, \ldots, n \\
d_{i} & =\sum_{j=1}^{n} d_{i j} \quad i=1, \ldots, m
\end{aligned}
$$

where $d_{i j}$ denotes the number of payoffs related to alternative $D_{j}$ which are worse than payoff $a_{i j}$. Symbol $m$ still signifies the number of scenarios and $p^{j}\left(a_{i j}\right)$ is the position of payoff $a_{i j}$ in the non-increasing sequence of all profits connected with decision $D_{j}$ (when $a_{i j}$ has the same value than at least one other payoff concerning a given alternative, then it is recommended to choose the farthest position of this value in the sequence-see Eq. 1). $d_{i}$ stands for the total number of "dominance cases" related to state $S_{i}$.

2. Assign an interval for the coefficient of optimism to each scenario (Eqs. 3-5).

The width of the range $(w)$ for each state of nature may be defined in the following way:

$$
w=\frac{1}{d_{\max }-d_{\min }+1}
$$

where $d_{\max }$ and $d_{\min }$ are the highest and the lowest number of "dominance cases" respectively. Such an approach allows to fit the width of the intervals to the difference between the highest and the lowest number of "dominance cases".

The extreme values $\left(b_{i}\right.$ and $\left.t_{i}\right)$ of a given interval, i.e. its endpoints, can be computed according to Eqs. (4-5):

$$
\begin{aligned}
b_{i} & =\max \left\{b \mid\left\{(b \mid w) \wedge\left(b \leq \frac{d_{i}-d_{\min }}{d_{\max }-d_{\min }}\right) \wedge(b \in[0 ; 1-w])\right\}\right\} \quad i=1, \ldots, m \\
t_{i} & =\min \left\{t \mid\left\{(t \mid w) \wedge\left(t \geq \frac{d_{i}-d_{\min }}{d_{\max }-d_{\min }}\right) \wedge(t \in[w ; 1]) \wedge\left(t=b_{i}+w\right)\right\}\right\} \\
i & =1, \ldots, m
\end{aligned}
$$

Additionally, let us assume that, apart from the interval(s) for the lowest number of "dominance cases", the intervals are left-open.

3. Find the set of values on the basis of which the decision maker $k$ will make the final choice:

$$
V(k)=\left\{v_{1}^{k}, v_{2}^{k}, \ldots, v_{j}^{k}, \ldots, v_{n}^{k}\right\}
$$


a. If parameter $\beta_{k}$ (i.e. the coefficient of optimism of DM $k$ ) belongs to the interval assigned to exactly one scenario, then that set contains all payoffs connected with this state of nature:

$$
\left.\left.\underset{i}{\exists !}\left(\beta_{k} \in\left[b_{i}, t_{i}\right] \vee \beta_{k} \in\right] b_{i}, t_{i}\right]\right) \Rightarrow V(k)=\left\{a_{i 1}, a_{i 2}, \ldots, a_{i j}, \ldots, a_{i n}\right\}
$$

b. If $\beta_{k}$ belongs to the interval assigned to more than one scenario, generate the set of values using Eqs. (8-9).

$$
\begin{aligned}
& \left.\left.\left.\underset{i}{\exists}\left(\beta_{k} \in\left[b_{i}, t_{i}\right] \vee \beta_{k} \in\right] b_{i}, t_{i}\right]\right)\right) \wedge\left(\left|S\left(S_{i}^{k}\right)\right|>1\right) \Rightarrow V(k)=\left\{A_{j, k}^{\text {arit }}\right\} \\
& A_{j, k}^{\text {arit }}=\frac{1}{\left|S\left(S_{i}^{k}\right)\right|} \sum_{S_{i} \in S\left(S_{i}^{k}\right)} a_{i j} j=1, \ldots, n
\end{aligned}
$$

where $S\left(S_{i}^{k}\right)$ is the set containing scenarios $S_{i}$ with an interval covering parameter $\beta_{k}$ and $\left|S\left(S_{i}^{k}\right)\right|$ denotes the cardinality of this set. $\left|S\left(S_{i}^{k}\right)\right|$ stands for the number of scenarios significant for decision maker $k$.

c. If $\beta_{k}$ does not belong to any interval assigned to scenarios, compute the set of values using Eqs. (10-11).

$$
\begin{aligned}
& \left.\left.\neg \underset{i}{\exists}\left(\beta_{k} \in\left[b_{i}, t_{i}\right] \vee \beta_{k} \in\right] b_{i}, t_{i}\right]\right) \Rightarrow V(k)=\left\{A_{j, k}^{\text {weig }(e, f)}\right\} \\
& A_{j, k}^{\text {weig }(e, f)}=\frac{\beta_{k}-t_{e}}{b_{f}-t_{e}} \cdot a_{f j}+\frac{b_{f}-\beta_{k}}{b_{f}-t_{e}} \cdot a_{e j} \quad j=1, \ldots, n
\end{aligned}
$$

where parameters $e$ and $f$ concern the scenarios which values of $\beta$ are a little lower (Eq. 12) and a little higher (Eq. 13) than parameter $\beta_{k}$. Parameters $t_{e}$ and $b_{f}$ signify the right endpoint of interval $e$ and the left endpoint of interval $f$, respectively. Finally, $a_{e j}$ and $a_{f j}$ constitute the payoffs connected with decision $D_{j}$ and scenarios $S_{e}$ and $S_{f}$.

$$
\begin{aligned}
S\left(S_{e}\right) & =\left\{S_{i} \mid\left(\left(\beta_{k}-t_{i}>0\right) \wedge\left(\beta_{k}-t_{i} \rightarrow \min \right)\right)\right\} \\
S\left(S_{f}\right) & =\left\{S_{i} \mid\left(\left(b_{i}-\beta_{k}>0\right) \wedge\left(b_{i}-\beta_{k} \rightarrow \min \right)\right)\right\}
\end{aligned}
$$

where $S\left(S_{e}\right)$ and $S\left(S_{f}\right)$ are sets containing scenarios $S_{e}$ and $S_{f}$, respectively. Note that if there are more than one state $S_{e}$ or $S_{f}$ (because of the occurrence of the same interval), then instead of $a_{e j}$ or $a_{f j}$, an arithmetic average of suitable payoffs is taken into consideration (Eqs. 14-15):

$$
\left(\left|S\left(S_{e}\right)\right|>1\right) \Rightarrow a_{e j}=\frac{1}{\left|S\left(S_{e}\right)\right|} \sum_{S_{i} \in S\left(S_{e}\right)} a_{i j}
$$




$$
\left(\left|S\left(S_{f}\right)\right|>1\right) \Rightarrow a_{f j}=\frac{1}{\left|S\left(S_{f}\right)\right|} \sum_{S_{i} \in S\left(S_{f}\right)} a_{i j}
$$

where $\left|S\left(S_{e}\right)\right|$ and $\left|S\left(S_{f}\right)\right|$ denote the cardinalities of sets $S\left(S_{e}\right)$ and $S\left(S_{f}\right)$.

4. a. Find alternative $D_{j(1)}^{k}$ which has the highest value in set $V(k)$ computed in step 3 :

$$
V_{j(1)}^{k}=\max _{j}\left\{v_{j}^{k}\right\}
$$

b. If decision $D_{j(1)}^{k}$ fulfils condition (17), it is the optimal one $\left(D_{j(1)}^{k}=D_{j}^{k *}\right)$.

$$
\begin{aligned}
& \underset{t \in\left\{1,2, \ldots, p_{k}\right\}}{\forall}\left(a_{t, j(1)} \geq w_{j}^{*}\right) \\
& p_{k}=\left\lceil\left(1-\beta_{k}\right) \cdot m\right\rceil=\left\lceil\alpha_{k} \cdot m\right\rceil \\
& a_{1, j(1)} \geq a_{2, j(1)} \geq \cdots \geq a_{t, j(1)} \geq \cdots \geq a_{p_{k}-1, j(1)} \geq a_{p_{k}, j(1)}
\end{aligned}
$$

where $p_{k}$ is the minimal number of scenarios whose payoffs should be at least equal to $w_{j}^{*}, a_{t, j(1)}$ fulfills Eq. (19) and stands for the outcome connected with decision $D_{j(1)}^{k}$ and scenario $S_{t}$. Symbol $w_{j}^{*}$ denotes the Wald's measure obtained for the optimal alternative according to the Wald's rule (see Eqs. 2021):

$$
\begin{aligned}
w_{j} & =\min _{i}\left\{a_{i j}\right\} \quad j=1, \ldots, n \\
w_{j}^{*} & =\max _{j}\left\{w_{j}\right\}
\end{aligned}
$$

If there are more than one decision fulfilling Eq. (16), only those which satisfy condition (17) are optimal.

c. If decision $D_{j(1)}^{k}$ does not satisfy Eq. (17), then find alternative $D_{j(2)}^{k}$ fulfilling condition (22). Such a decision always exists. It is the optimal one $\left(D_{j(2)}^{k}=\right.$ $\left.D_{j}^{k *}\right)$.

$$
\left(v_{j}^{k} \rightarrow \max \right) \wedge\left(\underset{t \in\left\{1,2, \ldots, p_{k}\right\}}{\forall}\left(a_{t, j} \geq w_{j}^{*}\right)\right)
$$

As we see, the last step of the SF+AS method provides a kind of security for pessimists and moderate decision makers. Lower the coefficient of optimism is, more certain is that the decision maker will not gain less than $w_{j}^{*}$.

\section{Case study}

Let us analyze the following example. Table 3 presents a payoff matrix. Profits are given in million Euro and concern a period of 1 year. There are four decision makers 
Table 3 Payoff matrix-Example II

\begin{tabular}{lclll}
\hline Scenarios & Alternatives & & \\
\cline { 2 - 5 } & $P 1$ & $P 2$ & $P 3$ & $P 4$ \\
\hline$S 1$ & 1 & 2 & 7 & 7 \\
$S 2$ & 5 & 4 & 1 & 6 \\
$S 3$ & 6 & 6 & 8 & 5 \\
$S 4$ & 10 & 3 & 9 & 5 \\
\hline
\end{tabular}

Table 4 Binary relation $R_{1}$ (according to P1)

\begin{tabular}{lllll}
\hline Scenarios & \multicolumn{2}{l}{ Scenarios } & $S 3$ & $S 4$ \\
\cline { 2 - 5 } & $S 1$ & $S 2$ & 0 & 0 \\
\hline$S 1$ & 0 & 0 & 0 & 0 \\
$S 2$ & 1 & 0 & 0 & 0 \\
$S 3$ & 1 & 1 & 1 & 0 \\
$S 4$ & 1 & 1 &
\end{tabular}

$S_{u}$ is better than $S_{w}$, if according to alternative P1, $a_{u 1}>a_{w 1}$.

Hence: $\forall S_{u}, S_{w} \in S\left(S_{i}\right): R_{1}\left(S_{u}, S_{w}\right) \Leftrightarrow a_{u 1}>a_{w 1}$.

$S\left(S_{i}\right)$ is the set of scenarios $S_{i}$. Notation $R_{1}\left(S_{u}, \mathrm{~S}_{w}\right)$ signifies that $S_{u}$ is $R_{1}$-related to $S_{w}$. When $S_{u}$ is $R_{1}$-related to $S_{w}$, then the bolean-valued function of relation $R_{1}$ is equal to 1 . Otherwise, this function equals 0 .

$\forall S_{u}, S_{w} \in S\left(S_{i}\right): f_{R_{1}}\left(S\left(S_{i}\right)\right)=1 \Leftrightarrow R_{1}\left(S_{u}, S_{w}\right)$

$\forall S_{u}, S_{w} \in S\left(S_{i}\right): f_{R_{1}}\left(S\left(S_{i}\right)\right)=0 \Leftrightarrow \neg R_{1}\left(S_{u}, S_{w}\right)$

For instance, $S_{1}$ is not $R_{1}$-related to $S_{2}$ because $a_{11}=1<a_{21}=5$. Thus, for pair $\left(S_{1}, S_{2}\right)$ function $f_{R_{1}}\left(S\left(S_{i}\right)\right)=0$. However, for pair $\left(S_{2}, S_{1}\right)$ function $f_{R_{1}}\left(S\left(S_{i}\right)\right)=1$, since $S_{2}$ is $R_{1}$-related to $S_{1}\left(a_{21}=\right.$ $\left.5>a_{11}=1\right)$

(DM1, DM2, DM3, DM4). They dispose of four possible strategies (projects P1, P2, $\mathrm{P} 3, \mathrm{P} 4)$ and they are aware of the fact that one out of four states of nature (S1, S2, S3, S4) will occur in the future, but they have no information about the likelihood of particular scenarios. Each decision maker has a different attitude towards risk. The first one is a pessimist, his coefficient of optimism equals $\beta_{1}=0.1$, the second one is a moderate pessimist $\left(\beta_{2}=0.4\right)$, the third one is a moderate optimist $\left(\beta_{3}=0.65\right)$ and the last one is a radical optimist $\left(\beta_{4}=0.95\right)$. This situation may signify that each decision maker has a totally unlike opinion about the true state of nature, i.e. the scenario that will really happen.

According to the concept of Pareto optimality (Ehrgott 2005) no scenario from Table 3 is dominated by other scenarios (Tables $4,5,6,7,8)$. All of them are Pareto optimal, since each column of Table 8 (representing the multicriteria comparison being the product of all binary relations) contains only zeros.

But even if all scenarios are Pareto optimal, one can observe that states S1 and S2 usually offer worse results than states $\mathrm{S} 3$ and $\mathrm{S} 4$ do. Therefore, we detect a possibility to work out a ranking of the considered states (see the first step of SF + AS). Theoretically, there are many procedures allowing to generate this ranking. For instance, one can use the criterion of the sum of payoffs for each scenario $(17,16,25$ and 27 , respectively), 
Table 5 Binary relation $R_{2}$ (according to P2)

$S_{u}$ is better than $S_{w}$, if according to alternative $\mathrm{P} 2$, $a_{u 2}>a_{w 2}$. Hence: $\forall S_{u}, S_{w} \in$ $S\left(S_{i}\right): S_{u} R_{2} S_{w} \Leftrightarrow a_{u 2}>a_{w 2}$

Table 6 Binary relation $R_{3}$ (according to P3)

$S_{u}$ is better than $S_{w}$, if according to alternative P3, $a_{u 3}>a_{w 3}$. Hence: $\forall S_{u}, S_{w} \in$ $S\left(S_{i}\right): S_{u} R_{3} S_{w} \Leftrightarrow a_{u 3}>a_{w 3}$

Table 7 Binary relation $R_{4}$ (according to P4)

$S_{u}$ is better than $S_{w}$, if according to alternative $\mathrm{P} 4$, $a_{u 4}>a_{w 4}$. Hence: $\forall S_{u}, S_{w} \in$ $\left.S\left(S_{i}\right): S_{u} R_{4} S_{w} \Leftrightarrow a_{u 4}>a_{w 4}\right)$

Table 8 Multicriteria comparison $W\left[R_{1}, R_{2}, R_{3}, R_{4}\right]$, i.e. the product of all binary relations $\left(S_{u}\right.$ dominates $S_{w}$, if for all decisions $P_{j}, S_{u}$ is better than $S_{w}$ )

\begin{tabular}{lllll}
\hline Scenarios & \multicolumn{2}{l}{ Scenarios } & & \\
\cline { 2 - 5 } & $S 1$ & $S 2$ & 0 & $S 4$ \\
\hline$S 1$ & 0 & 0 & 0 & 0 \\
$S 2$ & 1 & 0 & 0 & 1 \\
$S 3$ & 1 & 1 & 0 & 1 \\
$S 4$ & 1 & 0 & & 0 \\
\hline
\end{tabular}

\begin{tabular}{lllll}
\hline Scenarios & \multicolumn{2}{l}{ Scenarios } & & \\
\cline { 2 - 5 } & $S 1$ & $S 2$ & $S 3$ & $S 4$ \\
\hline$S 1$ & 0 & 1 & 0 & 0 \\
$S 2$ & 0 & 0 & 0 & 0 \\
$S 3$ & 1 & 1 & 1 & 0 \\
$S 4$ & 1 & 1 & & 0 \\
\hline
\end{tabular}

\begin{tabular}{lllll}
\hline Scenarios & \multicolumn{2}{l}{ Scenarios } & $S 3$ & $S 4$ \\
\cline { 2 - 5 } & $S 1$ & $S 2$ & 1 & 1 \\
\hline$S 1$ & 0 & 1 & 1 & 1 \\
$S 2$ & 0 & 0 & 0 & 0 \\
$S 3$ & 0 & 0 & 0 & 0 \\
$S 4$ & 0 & 0 & & \\
\hline
\end{tabular}

\begin{tabular}{lllll}
\hline Scenarios & \multicolumn{2}{l}{ Scenarios } & $S 3$ & $S 4$ \\
\cline { 2 - 5 } & $S 1$ & $S 2$ & 0 & 0 \\
\hline$S 1$ & 0 & 0 & 0 & 0 \\
$S 2$ & 0 & 0 & 0 & 0 \\
$S 3$ & 0 & 0 & 0 & 0 \\
\hline 4
\end{tabular}

the criterion of the sum of regrets (this time, the regrets would be calculated in relation to the best outcome connected with a given alternative, compare with the Savage's rule and see Table 9) or the criterion of the sum of utility functions/performance measures/implementation degrees (Gaspars-Wieloch 2012; Kukula 2000). Here we will apply the sum of "dominance cases" for each alternative (Table 10, e.g. scenario $\mathrm{S} 1$ is 4 times better than other events since for $\mathrm{P} 3: \mathrm{S} 1 \succ \mathrm{S} 2$, for $\mathrm{P} 4: \mathrm{S} 1 \succ \mathrm{S} 2, \mathrm{~S} 1 \succ \mathrm{S} 3$ and $\mathrm{S} 1 \succ \mathrm{S} 4)$. 
Table 9 Regrets computed in relation to the best outcome for particular alternatives-Example II

Table 10 Payoff matrix, sums of "dominance cases" and intervals for $\beta$-Example II

\begin{tabular}{llllll}
\hline Scenarios & \multicolumn{2}{l}{ Alternatives } & \multirow{2}{*}{ Sum of regrets } \\
\cline { 2 - 5 } & $P 1$ & $P 2$ & $P 3$ & $P 4$ & \\
\hline$S 1$ & 9 & 4 & 2 & 0 & 15 \\
$S 2$ & 5 & 2 & 8 & 1 & 16 \\
$S 3$ & 4 & 0 & 1 & 2 & 7 \\
$S 4$ & 0 & 3 & 0 & 2 & 5 \\
\hline
\end{tabular}

\begin{tabular}{llllllll}
\hline Scenarios & \multicolumn{1}{c}{ Alternatives } & & $\begin{array}{l}\text { Sum of "dominance } \\
\text { cases" }\left(d_{i}\right)\end{array}$ & Interval for $\beta$ \\
\cline { 2 - 4 } & $P 1$ & $P 2$ & $P 3$ & $P 4$ & \\
\hline$S 1$ & 1 & 2 & 7 & 7 & 4 & {$[0.00,0.25]$} \\
$S 2$ & 5 & 4 & 1 & 6 & 5 & ] $0.25,0.50]$ \\
$S 3$ & 6 & 6 & 8 & 5 & 7 & ] $0.75,1.00]$ \\
$S 4$ & 10 & 3 & 9 & 5 & 7 & $75,1.00]$ \\
\hline
\end{tabular}

Now, having a ranking of states of nature (I place: S3 and S4, II place: S2, III place: S1), one may attempt to assign a suitable interval of values of the coefficient of optimism to each scenario (see the second step of SF+AS and Eqs. 3-5):

$$
\begin{aligned}
w & =\frac{1}{7-4+1}=0.25 \\
b_{1} & =\max \left\{b \mid\left\{(b \mid 0.25) \wedge\left(b \leq \frac{4-4}{7-4}\right) \wedge(b \in[0 ; 0.75])\right\}\right\}=0.00, \\
t_{1} & =\min \left\{t \mid\left\{(t \mid 0.25) \wedge\left(t \geq \frac{4-4}{7-4}\right) \wedge(t \in[0.25 ; 1]) \wedge(t=0+0.25)\right\}\right\}=0.25, \\
b_{2} & =\max \left\{b \mid\left\{(b \mid 0.25) \wedge\left(b \leq \frac{5-4}{7-4}\right) \wedge(b \in[0 ; 0.75])\right\}\right\}=0.25 \\
t_{2} & =\min \left\{t \mid\left\{(t \mid 0.25) \wedge\left(t \geq \frac{5-4}{7-4}\right) \wedge(t \in[0.25 ; 1]) \wedge(t=0.25+0.25)\right\}\right\} \\
& =0.50, \\
b_{3} & =b_{4}=\max \left\{b \mid\left\{(b \mid 0.25) \wedge\left(b \leq \frac{7-4}{7-4}\right) \wedge(b \in[0 ; 0.75])\right\}\right\}=0.75 \\
t_{3} & =t_{4} \\
& =\min \left\{t \mid\left\{(t \mid 0.25) \wedge\left(t \geq \frac{7-4}{7-4}\right) \wedge(t \in[0.25 ; 1]) \wedge(t=0.75+0.25)\right\}\right\} \\
& =1.00 .
\end{aligned}
$$

One can observe two facts on the basis of the ranges set in Table 10: 
- more than one state of nature may contain the same interval (see scenarios S3 and S4),

- intervals do not have to cover the whole range of possible values for parameter $\beta$ (values greater than 0.5 and not exceeding 0.75 do not occur in our case).

According to the risk aversion declared by the decision makers, state S1 may be the true state in DM1's opinion $\left(\beta_{1}=0.1 \in[0.00,0.25]\right)$ and $\mathrm{S} 2$ may be selected by DM2 as the true scenario $\left.\left.\left(\beta_{2}=0.4 \in\right] 0.25,0.50\right]\right)$. There are two states (S3 and S4) which correspond to the DM4's level of optimism $\left.\left.\left(\beta_{4}=0.95 \in\right] 0.75,1.00\right]\right)$ and there is no scenario which can be directly assigned to the DM3's preferences $\left.\left.\left.\left.\left(\beta_{3}=0.65 \notin[0.00,0.25], \quad \beta_{3} \notin\right] 0.25,0.50\right], \quad \beta_{3} \notin\right] 0.75,1.00\right]\right)$. Therefore, it is recommended, in the DM4's case, to use for each decision an arithmetic average of the payoffs related to both states S3 and S4 (see Eqs. 8-9). On the other hand, for DM3 it is suggested to calculate a weighted average of outcomes related to the "nearest" scenarios i.e. S3, S4 and S2 following Eqs. (10-15).

Now, we can perform the second stage of the SF+AS method which consists in selecting the appropriate alternative (see the third and the fourth step of SF+AS):

a. DM1 makes his choice on the basis of the payoffs that can occur if scenario S1 takes place, see Eqs. (6), (7) and (16):

$$
\begin{aligned}
& V(1)=\left\{v_{1}^{1}, v_{2}^{1}, \ldots, v_{n}^{1}\right\}=\left\{a_{11}, a_{12}, a_{13}, a_{14}\right\}=\{1,2,7,7\}, \\
& V_{j(1)}^{1}=\max _{j}\left\{v_{j}^{1}\right\}=7 .
\end{aligned}
$$

Hence $D_{j(1)}^{1}=\mathrm{P} 3=\mathrm{P} 4$. Let us compute $p_{1}$ and $w_{j}^{*}$ according to Eqs. (18), (20), (21) and check whether both projects satisfy Eq. (17):

$$
\begin{aligned}
& p_{1}=\left\lceil\left(1-\beta_{1}\right) \cdot m\right\rceil=\lceil(1-0.1) \cdot 4\rceil=\lceil 0.9 \cdot 4\rceil=\lceil 3.6\rceil=4, \\
& w_{1}=\min \{1,5,6,10\}=1, w_{2}=2, w_{3}=1, w_{4}=5, \\
& w_{j}^{*}=\max \{1,2,1,5\}=5 .
\end{aligned}
$$

Thus, all payoffs ( $p_{1}$ equals 4 ) connected with $\mathrm{P} 3$ and $\mathrm{P} 4$ should be at least equal to $w_{j}^{*}=5$.

I. For P3: $a_{1,3}=9 \geq 5, a_{2,3}=8 \geq 5, a_{p_{1}-1,3}=a_{3,3}=7 \geq 5$, but $a_{p_{1}, 3}=$ $a_{4,3}=1<5$.

II. For P4: $a_{1,4}=7 \geq 5, a_{2,4}=6 \geq 5, a_{p_{1}-1,4}=a_{3,4}=5 \geq 5, a_{p_{1}, 4}=a_{4,4}=$ $5 \geq 5$.

Hence: $P 3=D_{j(1)}^{1} \neq D_{j}^{1 *}$ and $P 4=D_{j(1)}^{1}=D_{j}^{1 *}$. DM4 should select project P4.

b. DM2 ought to make the decision assuming that the payoffs related to state S2 will occur:

$$
\begin{aligned}
& V(2)=\left\{v_{1}^{2}, v_{2}^{2}, \ldots, v_{n}^{2}\right\}=\left\{a_{21}, a_{22}, a_{23}, a_{24}\right\}=\{5,4,1,6\}, \\
& V_{j(1)}^{2}=\max _{j}\left\{v_{j}^{2}\right\}=6 .
\end{aligned}
$$


Thus, he or she should choose project $\mathrm{P} 4\left(D_{j(1)}^{2}=\mathrm{P} 4\right)$. This time, $p_{2}$ equals 3 :

$$
p_{2}=\left\lceil\left(1-\beta_{2}\right) \cdot m\right\rceil=\lceil(1-0.4) \cdot 4\rceil=\lceil 0.6 \cdot 4\rceil=\lceil 2.4\rceil=3 .
$$

Let us check whether at least 3 payoffs related to $\mathrm{P} 4$ are greater or equal to 5:

$$
a_{1,4}=7 \geq 5, a_{p_{2}-1,4}=a_{2,4}=6 \geq 5, a_{p_{2}, 4}=a_{3,4}=5 \geq 5 .
$$

P4 fulfils assumption (17), so $P 4=D_{j(1)}^{2}=D_{j}^{2 *}$.

c. DM4 disposes of four arithmetic averages calculated by means of Eq. (9) and the data coming from scenarios S3 and S4:

$$
\begin{aligned}
A_{1,4}^{\text {arit }} & =\frac{1}{2}(6+10)=8.0, \quad A_{2,4}^{\text {arit }}=\frac{1}{2}(6+3)=4.5, \\
A_{3,4}^{\text {arit }} & =\frac{1}{2}(8+9)=8.5, \quad A_{4,4}^{\text {arit }}=\frac{1}{2}(5+5)=5.0, \\
V(4) & =\left\{A_{j, 4}^{\text {arit }}\right\}=\{8.0,4.5,8.5,5.0\} \\
V_{j(1)}^{4} & =\max _{j}\left\{v_{j}^{4}\right\}=8.5 .
\end{aligned}
$$

The results indicate that DM4 ought to be interested in project $\mathrm{P} 3$. This time, $p_{4}$ equals 1:

$$
p_{4}=\left\lceil\left(1-\beta_{4}\right) \cdot m\right\rceil=\lceil(1-0.95) \cdot 4\rceil=\lceil 0.05 \cdot 4\rceil=\lceil 0.2\rceil=1 .
$$

Let us check whether at least 1 payoff related to P3 is greater or equal to 5:

$$
a_{1,3}=a_{p_{4}, 3}=9 \geq 5
$$

P3 fulfils assumption (17), so $P 3=D_{j(1)}^{4}=D_{j}^{4 *}$.

d. DM3 has to analyze the figures obtained after using Eqs. (11), (13), (15) and the data concerning scenarios S2, S3 and S4:

$$
\begin{aligned}
& A_{1,3}^{\text {weig }(2,3+4)}=\frac{0.65-0.5}{0.75-0.5} \cdot 8+\frac{0.75-0.65}{0.75-0.5} \cdot 5=6.8, \\
& A_{2,3}^{\text {weig }(2,3+4)}=\frac{0.65-0.5}{0.75-0.5} \cdot 4.5+\frac{0.75-0.65}{0.75-0.5} \cdot 4=4.3, \\
& A_{3,3}^{\text {weig }(2,3+4)}=\frac{0.65-0.5}{0.75-0.5} \cdot 8.5+\frac{0.75-0.65}{0.75-0.5} \cdot 1=5.5, \\
& A_{4,3}^{\text {weig }(2,3+4)}=\frac{0.65-0.5}{0.75-0.5} \cdot 5+\frac{0.75-0.65}{0.75-0.5} \cdot 6=5.4 .
\end{aligned}
$$


Hence, it will be recommended to select project P1:

$$
\begin{aligned}
& V(3)=\left\{A_{j, 3}^{\text {weig }(2,3+4)}\right\}=\{6.8,4.3,5.5,5.4\}, \\
& V_{j(1)}^{3}=\max _{j}\left\{v_{j}^{3}\right\}=6.8 .
\end{aligned}
$$

Parameter $p_{3}$ equals 2:

$$
p_{3}=\left\lceil\left(1-\beta_{3}\right) \cdot m\right\rceil=\lceil(1-0.65) \cdot 4\rceil=\lceil 0.35 \cdot 4\rceil=\lceil 1.4\rceil=2
$$

Let us check whether at least 2 payoffs related to P1 are greater or equal to 5:

$$
a_{1,1}=10 \geq 5, a_{p_{3}, 1}=a_{2,1}=6 \geq 5
$$

P1 fulfils assumption (17), so $P 1=D_{j(1)}^{3}=D_{j}^{3 *}$.

Notice that if the original Hurwicz's rule was used for the levels of $\beta_{k}$ aforementioned, the following projects would be suggested: P4 for DM1 and DM2, P1 for DM3 and DM4.

\section{Conclusions}

The new approach presented in the paper and called the SF+AS method can be used in decision making under uncertainty when pure optimal alternatives are sought-after. The procedure is designed for decision makers who are able to declare their coefficient of optimism (pessimism). In contradiction to existing decision rules, this method contains an additional stage that precedes the searching of the optimal alternative and consists in forecasting the true state of nature on the basis of the DM's risk aversion. Such an approach signifies that the decision maker makes his or her choice by taking into consideration only the payoffs of the forecasted true scenario or the most probable (in his or her opinion) scenarios appointed in the first stage, and not the whole payoff matrix.

Note that successful attempts to forecast the true scenario have been already made for example by Guo $(2011,2013,2014)$, but in that case the proposed procedures are rather designed for DMPI and, furthermore, the most probable state of nature is set for each alternative separately (on the basis of some possibility degrees and satisfaction levels), which means that each decision may contain a different true scenario. In our contribution we were trying to find a global true scenario (i.e. the same one for all alternatives).

Hence, in this procedure the status (pessimistic, moderate or optimistic) of a given state of nature does not vary depending on the alternative, but is fixed for all decisions. Such a way of reasoning may be a good answer to the critical analysis of decision rules carried out by Officer and Anderson (1968) who claim that the nature is not a conscious opponent and it cannot change the "strategy" (i.e. the scenario) to minimize or maximize, for each choice of the decision maker's, his or her outcome. Additionally, the use of the DM's coefficient of optimism as a tool to forecast the true scenario has some common features with their opinion that: 
Table 11 Payoff matrix, sums of "dominance cases" and intervals for $\beta$-Example III

\begin{tabular}{lcrllll}
\hline Scenarios & \multicolumn{2}{l}{ Alternatives } & & & & $\begin{array}{l}\text { Sum of "dominance } \\
\text { cases" }\left(d_{i}\right)\end{array}$ \\
\cline { 2 - 5 } & $P 1$ & $P 2$ & $P 3$ & $P 4$ & & Interval for $\beta$ \\
\hline$S 1$ & 5 & 2 & 7 & 7 & 5 & ] $2 / 6,3 / 6]$ \\
$S 2$ & 1 & 11 & 1 & 4 & 3 & {$[0,1 / 6]$} \\
$S 3$ & 6 & 6 & 8 & 5 & 7 & ] $4 / 6,5 / 6]$ \\
$S 4$ & 10 & 3 & 9 & 5 & 8 & ] $5 / 6,1]$ \\
\hline
\end{tabular}

- uncertain decision problems for which it is not possible to estimate subjective probabilities do not exist,

- each uncertain decision problem (i.e. for which the objective likelihood is not known) may be reduced to a decision under risk.

Here, we do not define any subjective probabilities, however we try to find, in a subjective way, the most probable scenario, which is characteristic of DMUR.

Note that in some specific cases for a radical optimist the SF+AS method may lead to another solution than the maximax criterion does. If the highest outcome occurs for a scenario with $d_{i}<d_{\max }$, then suggestions given by both procedures may be different. According to the data and calculations concerning example III (Table 11), a radical optimist $(\beta=1)$ should choose project P2 if he or she follows the maximax decision rule, but the SF+AS method recommends project P1. This discrepancy is a result of the fact that the maximax rule evaluates a given scenario depending on payoffs related to a particular decision- $-\mathrm{S} 4$ is the most optimistic state of nature provided that projects P1 or P3 are selected, S2 is the best on condition that P2 is executed and $\mathrm{S} 1$ is the most advantageous if P4 is chosen. Hence, in this case, the status of the event is conditionally determined. Meanwhile, the SF+AS method appoints the most favourable scenario in a global way, which may signify that for a particular decision this state of nature does not offer the highest outcome.

A similar phenomenon will not happen for a radical pessimist $(\beta=0)$ due to Eqs. (17) and (22). In our example (Table 11) the Wald's criterion indicates project $\mathrm{P} 4$ and the SF+AS method suggests project P4 as well: $D_{j(1)}=\mathrm{P} 2$, but $D_{j(1)} \neq D_{j}^{*}$, because $p_{k}=4, w_{j}^{*}=4$ and two payoffs connected with P2 (i.e. 2 and 3) are lower than $w_{j}^{*}$ (see Eq. 17). P4 is project fulfilling Eq. (22): $a_{1,4}=7 \geq 4, a_{2,4}=5 \geq$ $4, a_{3,4}=5 \geq 4, a_{4,4}=4 \geq 4, \max _{j=1,3,4}\left\{v_{j}^{k}\right\}=\max \{1,1,4\}=4$.

In the description of the new approach it was recommended to establish the status of particular scenarios using the coefficient of optimism, but, of course, this step may be performed by appointing to each parameter $d_{i}$ an interval for the coefficient of pessimism since both indices $(\beta$ and $\alpha$ ) are interdependent and their sum always equals 1 .

As it was mentioned in previous sections, the SF + AS method does not impose us to forecast the true event by means of the sum of "dominance cases". The decision maker may apply another technique as well. He or she might use a different criterion or even 
perform a multicriteria analysis. Anyway, the sense of this procedure is to select the most probable scenario(s) by taking decision maker's preferences into consideration and then to choose the appropriate alternative on the basis of a reduced payoff matrix.

Open Access This article is distributed under the terms of the Creative Commons Attribution License which permits any use, distribution, and reproduction in any medium, provided the original author(s) and the source are credited.

\section{References}

Basili M (2006) A rational decision rule with extreme events. Risk Anal 26:1721-1728

Basili M, Chateauneuf A (2011) Extreme events and entropy: a multiple quantile utility model. Int J Approx Reason 52:1095-1102

Basili M, Chateauneuf A, Fontini F (2008) Precautionary principle as a rule of choice with optimism on windfall gains and pessimism on catastrophic losses. Ecol Econ 67:485-491

Basili M, Zappia C (2010) Ambiguity and uncertainty in Ellsberg and Shackle. Camb J Econ 34(3):449-474

Branzei R, Alparslan Gok SZ, Branzei O (2011) Cooperative games under interval uncertainty: on the convexity of the interval undominated cores. Cent Eur J Oper Res 19(4):523-532

Cannon CM, Kmietowicz ZW (1974) Decision theory and incomplete knowledge. J Manag Stud 11(3):224232

Chateauneuf A, Cohen M (2000) Choquet expected utility model: A new approach to individual behaviour under uncertainty and to social welfare. In: Grabisch M, Murofushi T, Sugeno M (eds) Fuzzy measures and integrals: theory and applications. Physica, Heidelberg, pp 289-313

Chronopoulos M, De Reyck B, Siddiqui A (2011) Optimal investment under operational flexibility, risk aversion, and uncertainty. Eur J Oper Res 213:221-237

Ehrgott M (2005) Multicriteria optimization. Springer, Berlin

Ellsberg D (2001) Risk, ambiguity and decision. Garland Publishing, New York

Etner J, Jeleva M, Tallon JM (2012) Decision theory under ambiguity. J Econ Surv 26(2):234-270

Gaspars-Wieloch H (2012) Limited efficiency of optimization methods in solving economic decision problems. Ekonomista 2012(3):303-324

Gaspars-Wieloch H (2013a) Modifications of the Hurwicz's decision rules. Cent Eur J Oper Res. doi:10. 1007/s10100-013-0302-y

Gaspars-Wieloch H (2013b) On a decision rule supported by a forecasting stage based on the decision maker's risk aversion. In: Zadnik Stirn L, Zerovnik J, Povh J, Drobne S, Lisec A (eds), Proceedings of the 12th international symposium of operational research, pp 53-59

Gaspars-Wieloch H (2014a) On a decision rule for mixed strategy searching under uncertainty on the basis of the coefficient of optimism. Procedia Soc Behav Sci 110:923-931

Gaspars-Wieloch H (2014b) Propozycja hybrydy reguł Hurwicza i Bayesa w podejmowaniu decyzji w warunkach niepewności. In: Trzaskalik T (ed) Modelowanie preferencji a ryzyko 2014, Studia Ekonomiczne. Zeszyty Naukowe Wydzialowe Uniwersytetu Ekonomicznego w Katowicach, Katowice, 74-92

Ghirardato P, Maccheroni F, Marinacci M (2004) Differentiating ambiguity and ambiguity attitude. J Econ Theory 118:133-173

Gilboa I (2009) Theory of decision under uncertainty. Cambridge University Press, Cambridge

Gilboa I, Schmeidler D (1989) Maxmin expected utility with non-unique prior. J Math Econ 18:141-153

Groenewald ME, Pretorius PD (2011) Comparison of decision making under uncertainty investment strategies with the money market. J Financ Stud Res. doi:10.5171/2011.373376

Guo P (2011) One-shot decision theory. IEEE Trans Syst Man Cybern Part A 41(5):917-926

Guo P (2013) One-shot decision making with regret. In: International conference on information science and technology (ICIST), pp 493-495. doi:10.1109/ICIST.2013.6747596

Guo P (2014) One-shot decision theory: a fundamental alternative for decision under uncertainty. In: Humancentric decision-making models for social sciences, pp 33-55

Haimann T, Scott WG, Connor PE (1985) Management. Houghton Mifflin Company, Boston

Hayashi T (2006) Regret aversion and opportunity-dependence. University of Texas, Austin 
Hurwicz L (1951) The generalized Bayes minimax principle: a criterion for decision making under uncertainty. Cowles Commission Discussion Paper, Statistics 335

Hurwicz L (1952) A criterion for decision making under uncertainty. Technical Report 355. Cowles Commission

Huynh VN, Hu C, Nakamori Y, Kreinovich V (2009) On decision making under interval uncertainty: a new justification of Hurwicz optimism-pessimism approach and its use in group decision making. In: Proceedings of the 39th international symposium on multiple-valued logic ISMV/L/2009, Naha, Okinava, Japan, May 21-23, 2009, pp 214-220

Ioan C, Ioan G (2011) A method of choice of the best alternative in the multiple solutions case in the games theory. J Account Manag 1(1):5-8

Karni E (1985) Decision making under uncertainty. The case of state-dependent preferences. Harvard University Press, Cambridge

Karni E, Schmeidler D, Vind K (1983) On state dependent preferences and subjective probabilities. Econometrica 51:1021-1031

Kmietowicz ZW, Pearman AD (1984) Decision theory, linear partial information and statistical dominance. Omega 12:391-399

Kofler E (1993) Podejmowanie decyzji przy niepełnej informacji. Real Publishers, Zurich

Kukula K (2000) Metoda unitaryzacji zerowanej. PWN, Warszawa

Knight FH (1921) Risk, uncertainty, profit. Hart. Schaffner \& Marx; Houghton Mifflin Co., Boston

Luce RD, Raiffa H (1957) Games and decisions. Wiley, New York

Marinacci M (2002) Probabilistic sophistication and multiple priors. Econometrica 70:755-764

Michalska E (2014) Zastosowanie wskaznika Omega w podejmowaniu decyzji przy niepelnej informacji liniowej. In: Gajda JB (ed) Metody i zastosowania badan operacyjnych 2013. Wydawnictwo Uniwersytetu Lodzkiego, Lodz

Milnor J (1954) Games against nature. In: Thrall RM, Coombs CH, Davis RL (eds) Decision processes. Wiley, New York, pp 49-60

Nakamura K (1986) Preference relations on a set of fuzzy utilities as a basis for decision making. Fuzzy Sets Syst 20:147-162

Niehans J (1948) Zur preisbildung bei ungewissen erwartungen. Schweizerische Zeitschrift fur Volkswirtschaft und Statistik 84(5):433-456

Officer RR, Anderson JR (1968) Risk, uncertainty and farm management decisions. Rev Market Agric Econ 36(1):3-19

Pazek K, Rozman C (2009) Decision making under conditions of uncertainty in agriculture: a case study of oil crops. Poljoprivreda (Osijek) 15(1):45-50

Piasecki K (1990) Decyzje i wiarygodne prognozy. Akademia Ekonomiczna w Poznaniu, Poznań

Puppe C, Schlag K (2009) Choice under complete uncertainty when outcome spaces are state dependent. Theory Decis 66:1-16

Render B, Stair RM, Hanna ME (2006) Quantitative analysis for management. Pearson Prentice Hall, Upper Saddle River

Savage LJ (1961) The foundations of statistics reconsidered. In: Kyburg HE, Smokler HE (eds) Studies in subjective probability. Wiley, New York, pp 173-188

Sikora W (ed) (2008) Badania operacyjne. Polskie Wydawnictwo Ekonomiczne, Warszawa

Trzaskalik T (2008) Wprowadzenie do badań operacyjnych z komputerem, 2nd edn. Polskie Wydawnictwo Ekonomiczne, Warszawa

Tversky A, Kahneman D (1992) Advances in prospect theory: cumulative representation of uncertainty. J Risk Uncertain 5:297-323

von Neumann J, Morgenstern O (1944) Theory of games and economic behavior. Princeton University Press, Princeton

Wald A (1950a) Basic ideas of a general theory of statistical decisions rules. In: Wald A (ed) Selected papers in statistics and probability. McGraw-Hill, New York, pp 656-668

Wald A (1950b) Statistical decision functions. Wiley, New York

Weber M (1987) Decision making with incomplete information. Eur J Oper Res 28:44-57

Xiaogang W, Rongwei D (2012) A solution to decision making under uncertainty. J Theor Appl Inf Technol 45(1):320-324 